* Cómo citar este artículo: Homann, F. (2021). Memoria colectiva e intertextualidad: las funciones mnemotécnicas de la tradición literaria en la narrativa de Juan Gabriel Vásquez y Héctor Abad Faciolince. Estudios de Literatura Colombiana 49, pp. 193-211. DOI: https://doi.org/10.17533/udea.elc.n49a11

1 https://orcid.org/0000-0001-5238-1923 fhomann@uni-muenster.de Universität Münster, Deutschland
Editores: Andrés Vergara Aguirre, Christian Benavides Martínez

Recibido: 13.02 .2021

Aprobado: 21.05.2021

Publicado: 30.06 .2021

Copyright: (2021 Estudios de Literatura Colombiana. Este es un artículo de acceso abierto distribuido bajo los términos de la Licencia Creative Commons AtribuciónNo comercial - Compartir igual 4.0 Internacional

\section{Memoria colectiva e INTERTEXTUALIDAD: LAS FUNCIONES MNEMOTÉCNICAS DE LA TRADICIÓN \\ LITERARIA EN LA NARRATIVA DE JUAN GABRIEL VÁSQUEZ Y HÉCTOR ABAD FACIOLINCE*}

\author{
Collective Memory and \\ Intertextuality: The MNemonic \\ Functions of Literary Tradition in the \\ Narrative of Juan Gabriel Vásquez and \\ HÉctor Abad Faciolince
}

Florian Homann ${ }^{1}$

\begin{abstract}
Resumen: Este artículo trata la relación entre literatura, intertextualidad y memoria, temas dominantes en la narrativa de Vásquez y Abad Faciolince, profundizando en las funciones de la tradición literaria en el discurso memorístico. Se aplica la noción de los elementos intertextuales como figuras de memoria; según esta idea, un texto literario puede convertirse en símbolo de la memoria de una comunidad. En las novelas analizadas, unos poemas concretos desempeñan papeles centrales, poniendo de manifiesto que los intertextos cumplen funciones cruciales como medios de la memoria cultural: citar determinadas obras puede crear la sensación de recordar un pasado compartido, representado en la literatura.
\end{abstract}

Palabras clave: memoria colectiva; intertextualidad; poesía; Juan Gabriel Vásquez; Héctor Abad Faciolince.

Abstract: This paper explores the relationship between
literature, intertextuality and memory, central topics in the
narrative of Vásquez and Abad Faciolince, examining in
detail the functions of literary tradition in memory discourse.
Collective memory can be manifested in literature by the use
of intertextuality and symbolic figures of memory: a literary
text can be transformed by intertextual strategies in a symbol
of the memory of a cultural area. In the analysed novels,
certain poems are crucial intertexts, as they can create the
sensation of a shared past, represented in literature.

Keywords: collective memory; intertextuality; poetry; Juan Gabriel Vásquez; Héctor Abad Faciolince. 
Estaba pensando en la Casa de Poesía [...]. Uno de sus salones era un lugar único en Bogotá: allí, los letraheridos de todas las calañas iban a sentarse en sofás de cuero mullido, junto a equipos de sonido de una cierta modernidad, y escuchaban hasta cansarse grabaciones ya legendarias: Borges en la voz de Borges, García Márquez en la voz de García Márquez, León de Greiff en la voz de León de Greiff (Vásquez, 20II, p. 44).

\section{La memoria colectiva en la narrativa de $\mathbf{H}$. Abad Faciolince y J. G. Vásquez}

Hoy en día, las investigaciones sobre la relación entre literatura, memoria colectiva y culturas del recuerdo tienden a corroborar que no existe una única memoria estable, sino que resulta más pertinente hablar de diversas memorias heterogéneas y dinámicas, que a su vez se encuentran en competencia para ejercer su influencia sobre lo que se denomina la memoria cultural de una determinada comunidad (Erll, 2012, pp. 45-49). Con respecto a su tratamiento en la literatura, resulta pertinente examinar los textos narrativos de dos escritores colombianos contemporáneos: Juan Gabriel Vásquez, de cuyas novelas me voy a centrar en este estudio en El ruido de las cosas al caer (2011), y Héctor Abad Faciolince, del cual voy a recurrir a El olvido que seremos (2006). Ambos autores tienen en común el enfoque en el tratamiento temático del campo de la memoria, tanto a nivel individual como colectivo. En relación con ello, se hace notar con frecuencia el aspecto de la intertextualidad, además de un marcado carácter metaficcional, aludiendo continuamente a otros textos literarios. La narrativa de cada uno puede leerse en su conjunto realmente como una obra, un mosaico de múltiples referencias intertextuales a los textos clásicos y también a los propios escritos anteriores. ${ }^{1}$

Respecto a las recuperaciones de determinadas experiencias individuales que pueden ser representativas para una memoria comunicativa, resulta fructífero investigar sobre las funciones específicas de la notable intertextualidad y la inserción de elementos de la memoria cultural, en concreto, examinar la incorporación de ciertas obras narrativas anteriores y textos renombrados de otros géneros, especialmente la poesía, en los textos narrativos. ¿En qué medida las inserciones de unos intertextos culturales los convierten en simbólicas figuras de memoria para transmitir ciertos recuerdos de un colectivo? Para contestar a esta pregunta, este artículo primero ofrece una definición de los conceptos específicos, que se aplican en esta investigación, con respecto a la memoria colectiva de una cultura y los distintos modos de su puesta en escena en la literatura. A continuación, se puntualizan las ideas de las figuras de

Se trata además de dos escritores que se aprecian e influencian mutuamente, por ejemplo, Héctor Abad Faciolince ha redactado la reseña "La música del ruido" sobre la novela de 2011 del escritor bogotano. 
memoria y el papel de la intertextualidad, en relación con las nociones tanto de una memoria comunicativa como de una cultural, para aplicar estas ideas a las novelas y analizar las funciones de los intertextos narrativos y de los poemas incrustados, en cuanto medios de la memoria colectiva.

\section{Distintas dimensiones del recordar, figuras de memoria e intertextualidad}

Según los estudios recientes, cada memoria, sea individual o colectiva, necesita una activación en forma de una articulación a través de la narración. Debido a que esta narración se realiza desde la perspectiva del presente, la memoria colectiva se considera un fenómeno extraordinariamente alterable. Existe un consenso bajo el cual el pasado no es un hecho acabado y estable, sino un constructo sociocultural que depende de los actos performativos de recordar y narrar el pasado desde distintas perspectivas. De tal manera que los estudios actuales se enfocan tanto en los procesos dinámicos del recordar como en la pluralidad y alteridad de las memorias colectivas contemporáneas, llamativamente heterogéneas. Así, en una sociedad pueden existir varias memorias que compiten con un discurso memorístico hegemónico y oficial, y que pueden estar puestas en escena en la literatura (Erll, 2012, pp. 97-111).

Jan Assmann (2011) sostiene que cada memoria colectiva está compuesta por una memoria comunicativa y una memoria cultural, y presenta distintos aspectos en los que se diferencian los dos componentes. Lo más relevante aquí es que cada uno de estos tipos integrantes de memoria corresponde a un horizonte temporal determinado, o bien cercano o bien lejano. Mientras que la memoria comunicativa se expresa en las comunicaciones cotidianas y la transmisión oral de ciertos relatos de experiencias vividas en el pasado reciente, por lo que se ubica en un marco temporal cercano de aproximadamente ochenta hasta cien años, la memoria cultural, en cambio, se manifiesta en rituales y mitos de un pasado absoluto y fundador de una cultura, en aquel lado lejano de una frontera temporal, el así denominado floating gap (Assmann, 2011, pp. 47-58). Erll (2012, pp. 157-162) revisa esta distinción para su aplicación en los estudios de literatura contemporánea, por lo que diferencia entre un horizonte social cercano, incluyendo la experiencia vital de los testigos directos, y un horizonte cultural lejano, en relación con lo monumental que tiene un significado para toda la formación cultural.

Con respecto a la recepción de ciertos textos ficcionales, leídos estos como medios de una memoria colectiva, Erll (2012) ha desarrollado un concepto denominado 
novelas de la memoria. Para fundamentar esta conceptualización, recurre a criterios narratológicos para proyectar la concepción de una retórica de la memoria colectiva (p. 260), distinguiendo entre unos modos específicos de narrar sobre el pasado. Basándose en la distinción entre una memoria comunicativa y una cultural, Erll presenta diversos criterios para identificar dos registros literarios particulares, denominados modo asociado con la experiencia y modo monumental. Por un lado, en "el modo asociado con la experiencia, lo relatado se muestra como objeto de la memoria comunicativa cotidiana” (p. 230), recordando el pasado reciente. Por el otro lado, en "el modo monumental, lo representado se muestra como objeto vinculante de un horizonte cultural amplio (nacional, religioso) de sentido, en cuanto mito de la memoria cultural vinculante" (p. 230), es decir, se refiere al horizonte cultural lejano. Podemos observar que las novelas de Héctor Abad Faciolince y Juan Gabriel Vásquez tienden hacia el modo asociado con la experiencia y ponen en escena determinadas memorias comunicativas y cotidianas de ciertos colectivos o grupos sociales. Además, mi lectura de la narrativa de ambos autores como novelas de la memoria va de la mano con la comprensión de que la literatura es capaz de llevar los contenidos de una memoria más bien personal y ordinaria, con las experiencias del pasado reciente en un horizonte social cercano, a la dimensión cultural. En otras palabras, un texto literario puede transferir una memoria comunicativa, basada en conversaciones cotidianas, y una memoria cultural, notablemente inestable, mediante la ficcionalización y universalización de los recuerdos en la puesta en escena en la literatura, entendida como medio artístico y cultural de la memoria colectiva.

El hecho de que en todas las culturas surjan elementos simbólicos para la memoria colectiva ha animado a Assmann a desarrollar la idea de figuras de memoria para concebir los diversos objetos y topoi que sirven para la materialización de la memoria cultural. En esta concepción incluye todos los lugares y las imágenes en los que se condensan las memorias colectivas de una cultura del recuerdo, que también pueden considerarse entes simbólicos, tales como edificios, ritos, obras de arte y textos literarios.

Hasta hoy se han presentado diversas interpretaciones del concepto intertextualidad. Camarero (2008) subraya la característica del diálogo entre los textos, que puede establecerse entre múltiples textos y géneros literarios, y menciona unas redes o tejidos relacionales entre los diversos intertextos que un lector puede detectar en la literatura que lee o que conoce; en este contexto, alude a una metafórica biblioteca: 
La literatura, en toda su vasta extensión universal, viene a ser como una gran biblioteca y los fondos contenidos en ella, el tesoro acumulado de miles de obras, nos proporcionan la posibilidad de establecer una red de relaciones de todo tipo entre sus textos (p. 23).

Por su parte, Scheiding conecta los resultados de los estudios sobre la intertextualidad con los recuerdos a un pasado compartido por una comunidad para declarar que estos tejidos forman parte de la memoria colectiva de una cultura. Según Scheiding (2005), los textos literarios participan en el metafórico "memory theater of a culture" (p. 53) como tejidos de fragmentos y citas de las diversas fuentes del pasado. En la misma línea, Erll (2012, pp. 87-94) incluye entre los distintos tipos de medios materiales de la memoria colectiva una memoria del arte / la literatura, refiriéndose a la reelaboración literaria de elementos selectos de las obras anteriores de la tradición artística. Esta idea va de la mano con la declaración de Lachmann (2010) de que la literatura constituye una determinada memoria de una cultura, que también se recrea continuamente, gracias a las diferentes interpretaciones del pasado:

Literature is culture's memory, not as a simple recording device but as a body of commemorative actions that include the knowledge stored by a culture, and virtually all texts a culture has produced and by which a culture is constituted. Writing is both an act of memory and a new interpretation, by which every new text is etched into memory space (p. 30r).

Si tenemos en cuenta que un texto literario renombrado puede condensar los recuerdos colectivos del pasado, la tradición literaria es capaz de cumplir funciones mnemotécnicas más que relevantes en cuanto a la memoria colectiva, ante todo, en su dimensión cultural. Así, las referencias intertextuales conceden cierta reputación a las nuevas obras que las citan, puesto que las "obras literarias cobran autoridad a partir de la literatura anterior, al relacionarse con los textos canónicos y clásicos" (Erll, 2012, p. 234). En conclusión, al citar o aludir a textos anteriores se funda una identidad cultural entre un autor y sus lectores, gracias a la capacidad de crear la sensación de recordar un pasado en común, a través del conocimiento de la misma literatura. Según estas teorías, la biblioteca intertextual mencionada puede equivaler a la memoria cultural de un colectivo y los propios intertextos sirven como verdaderas figuras de memoria. En síntesis, para cumplir el objetivo de transformar una memoria comunicativa en memoria cultural, se ofrece combinar el registro narrativo asociado a la experiencia directa, que posibilita articular los recuerdos del pasado reciente de manera más inmediata y creíble posible, con un uso frecuente de determinadas figuras de memoria y de las estrategias intertextuales. 


\section{Los distintos modos narrativos de presentar los recuerdos}

En las novelas analizadas se manifiesta una memoria comunicativa propia expresada a nivel de su narración literaria en el modo asociado a la experiencia. Un indicio para este registro narrativo es el uso del yo como instancia narradora. En general, los textos literarios de Abad Faciolince pueden considerarse como figuraciones del yo (Capote, 2019, p. 37). De los diversos escritos del antioqueño, un ejemplo muy pertinente para una narración que se lee como novela de la memoria, salpicada además de múltiples referencias intertextuales, es El olvido que seremos. Se trata de una novela sobre la memoria individual y a la vez representativa para un colectivo en la que

[...] si de algún sentido es portador este yo autofictivo y figurativo de Abad Faciolince, éste es, sin duda, del discurso de lo memorístico, un componente que aparece como telón de fondo y elemento sustancial en su narrativa y, de manera evidente, en El olvido que seremos. El discurso de la memoria, complementario al de historia, se entiende como un proceso de recuperación de las experiencias individuales, en este caso, de las víctimas de la violencia, con un sentido colectivo, simbólico y representativo de toda una comunidad (Capote, 2019, p. 39).

Vividas en el pasado reciente y en un horizonte personalmente experimentable, en la novela mencionada las experiencias particulares se ubican dentro del marco temporal de una transmisión entre tres generaciones, algo característico para la memoria comunicativa. Desde la perspectiva del mismo Abad Faciolince (2006), como "un niño de la mano de su padre” (p. 11), se cuenta la vida del médico Héctor Abad Gómez en un relato que oscila entre biografía novelada y autoficción de la propia infancia del escritor. El tema dominante es la historia familiar, en la que ese "médico contra el dolor y el fanatismo" (p. 40), que por su ideología y compromiso político fue asesinado en 1987, se describe mayoritariamente a través de la relación que mantenía con su hijo. El elemento trasferible a una dimensión colectiva de la memoria es el terror político, ya que el asesinato del médico, que luchaba sin cesar por los derechos humanos, instaura la persecución de muchos intelectuales en Colombia inconformes con las circunstancias establecidas y, por tanto, representantes de una memoria subalterna. ${ }^{2}$ Así, se da testimonio literario de esta manifestación específica de memoria comunicativa, transmitida desde entonces de forma oral en diversas conversaciones víctimas a ejecutar, publicada en 1987: a excepción de Alberto Aguirre y Carlos Gaviria, que se refugiaron a tiempo en el exilio, todos los amenazados fueron asesinados. 
cotidianas de los contemporáneos y testigos directos de los hechos. ${ }^{3}$ Para expresar este tipo de memoria en la dimensión del horizonte social cercano, se ofrece el modo narrativo asociado a la experiencia y, de hecho, se cumplen varios criterios más de este registro literario. Por ejemplo, la mención explícita de los acontecimientos realmente ocurridos se lleva a cabo con la indicación exacta de sus lugares y fechas, que dejan ubicar la trama en un espacio temporal concreto y cercano. Como ya se ha dicho, un indicio para el registro literario vinculado a la experiencia directa es, en general, el narrador en primera persona:

El narrador I-as-witness que está en los testimonios presenciales y que asocia lo vivido con la observación de las experiencias de los otros [...] puede contribuir a la escenificación literaria de la función portadora que cumplen las memorias comunicativas en el texto literario (Erll, 2012, p. 23\%).

De este modo, el yo de la novela da testimonio de lo inmediatamente experimentado y, en consecuencia, se relaciona inexorablemente con la intimidad y subjetividad características de la poesía lírica. Después del asesinato, el narrador guarda como un recuerdo personal la camisa manchada de sangre que su padre llevó ese día, en cuyo bolsillo encuentra un poema copiado a mano por el médico. Además, el único hijo varón tiene la tarea íntima y desagradable de "abrir los cajones" (Abad Faciolince, 2006, p. 224) en la oficina y gestionar el legado del padre: al explorar este lugar de memoria, encuentra una multitud de recuerdos personales condensados en documentos, cartas, fotos y otros numerosos medios de la memoria, en su mayoría desconocidos por la familia. Además de estos cajones, un lugar de memoria por excelencia es la biblioteca inmensa del padre. Su mención frecuente en la trama revela la estrecha relación cuadrangular entre la memoria cultural, la memoria individual de Héctor Abad Gómez, la literatura y la intertextualidad en la novela, ya que el médico sabía recitar incontables poemas de memoria, entre otros, las creaciones de tono político de Machado, Vallejo y Neruda. Además, le leía a su hijo las creaciones de los "grandes autores necesarios para una 'liberal education', como decía el prólogo de la colección de Clásicos de la Enciclopedia Británica, unos cincuenta volúmenes encuadernados en falsa piel, con las obras más importantes de la cultura combina en ese episodio sus recuerdos propios con un collage de las remembranzas de sus cinco hermanas y de otras personas: se nota que la memoria no es de ninguna forma estática, sino que cada uno se acuerda de forma distinta. 
occidental" (p. 82). En este símbolo de la biblioteca extensa, manifestando el extraordinario conocimiento literario del intelectual de Jericó, la cotidianidad de los recuerdos literarios y la dimensión cultural se ven entretejidas, de lo que se puede deducir que el tejido denso de referencias intertextuales, aludiendo o mencionando a reconocidos hipotextos tanto poéticos como narrativos, constituye una clave en esta novela. Llamativo es que el narrador explicita que el tema de la muerte constituye de hecho un motivo tratado con preferencia y gran belleza artística en la tradición literaria hispánica, particularmente en la poesía lírica: "La presencia y conciencia de la muerte es una de las facetas más marcadas de la lírica clásica castellana” (p. 229). Así, el narrador recurre con preferencia a obras líricas cuando describe la muerte de su propio padre.

Además, las mencionadas referencias intertextuales dentro de la misma obra de Abad Faciolince se vuelven cruciales en el caso de El olvido que seremos, ya que establecen una insólita red de relaciones entre esta novela y sus demás creaciones. Anteriormente a la novela, Abad Faciolince describe su infancia y la vida de su padre en el poema "Memento", publicado posteriormente en la antología poética Testamento involuntario. "Un poema en el bolsillo", el primer texto del libro Traiciones de la memoria, de carácter ensayístico, presenta efectivamente los resultados de una investigación del mismo autor sobre el soneto "Aquí/Hoy", el texto encontrado en la camisa de su padre, cuyo primer verso da el título a su novela de 2006. La novela posterior, La Oculta, contiene muchos elementos de El olvido que seremos y se puede considerar una obra de ficción con notables influencias autobiográficas. ${ }^{4}$ Así, cada obra constituye un mosaico de piezas de numerosas obras anteriores, de múltiples voces y recuerdos literarios.

Así mismo, el escritor bogotano Juan Gabriel Vásquez es conocido por la trasferencia de determinados elementos de una memoria comunicativa en manifestaciones de una memoria cultural y literaria, mediante las transformaciones de recuerdos individuales en representaciones de una memoria social, realizadas a nivel narrativo en el modo asociado a la experiencia. El ruido de las cosas al caer (2011) es en cierta manera emblemática para su narrativa, puesto que evidentemente puede leerse como novela de la memoria: a nivel temático, trata principalmente los multifacéticos pro-

$4 \quad$ La finca que da el título a la novela existe realmente y pertenece a unos familiares del escritor. Además, los protagonistas mantienen paralelismos notables con Abad Faciolince y su familia. 
cesos del recordar, omnipresentes en toda su obra. En una entrevista realizada por De Maeseneer y Vervaeke (2013), Vásquez responde a la pregunta por diferencias y paralelismos entre sus primeras novelas publicadas en el siglo xx: "Las tres novelas tienen en común una obsesión que me va a acompañar siempre: la obsesión por la memoria, por el hecho de recordar" (p. 210).

En El ruido de las cosas al caer es un narrador que no comparte nombre con el escritor quien describe desde la primera persona singular las consecuencias del narcotráfico en la Bogotá de los años 80 y 90 para la sociedad colombiana. Al ver en 2009 las noticias de la caza de un hipopótamo que se había escapado del zoológico de Pablo Escobar, Antonio Yammara se acuerda de Ricardo Laverde, un conocido que fue asesinado en su presencia en 1995. A continuación, narra dos relatos intercalados: por un lado, recuerda una parte de su propia vida entre 1994 y 1999, y por el otro lado, cuenta el pasado del piloto Laverde, reconstruido a través de una reunión con su hija Maya Fritts en 1999. De tal manera, se entrelazan una memoria personal y una memoria compartida por un grupo social. En el encuentro, Antonio y Maya se identifican por compartir la memoria propia de una generación, la de todas las personas nacidas a inicios de los 70 y crecidas en la Bogotá de los 80, experimentando en directo el auge de la violencia vinculada al narcotráfico. La retórica de la memoria colectiva se asocia fuertemente a la experiencia inmediata y tanto estas experiencias como los recuerdos individuales de los protagonistas constituyen lo emblemático para un grupo más grande. De tal manera que los dos personajes pueden ser considerados representantes de un colectivo específico y de una cultura del recuerdo particular:

El narrador que Vásquez creó para esta novela sugiere en repetidas ocasiones que su relato es el de toda una generación, y hace constantes alusiones al problema colectivo que estaba enfrentando Colombia a partir de los años ochenta. Reflexiones personales sobre temas como la violencia, el miedo y la vulnerabilidad, desembocan siempre en afirmaciones que revelan su pretensión de iluminar la realidad colectiva con su relato (Aristizábal, 2019, p. 42).

Esta memoria generacional de la que los miembros del colectivo deducen su identidad compartida se apoya en los recuerdos a determinados acontecimientos trascendentales, que son en este caso tanto los asesinatos de Rodrigo Lara Bonilla y Luis Carlos Galán como el atentado al vuelo 203 de Avianca. Erll (2012, p. 72) refiere al ejemplo del 9/11 para argumentar que también ciertas fechas significativas pueden tener la función de apoyo para los recuerdos compartidos y considerarse figuras de 
memoria. Los tres eventos debatidos en la novela (Vásquez, 2011, pp. 227-229) -bajo la pregunta de qué hacía el interlocutor esos días- constituyen referencias culturales importantes y se convierten en figuras de memoria, sobre las cuales conversan los miembros del colectivo para asegurarse de determinadas experiencias del pasado en común:

La gente de mi generación hace estas cosas: nos preguntamos cómo eran nuestras vidas al momento de aquellos sucesos, casi todos ocurridos durante los años ochenta, que las definieron o las desviaron sin que pudiéramos siquiera darnos cuenta de lo que nos estaba sucediendo. Siempre he creído que así, comprobando que no estamos solos, neutralizamos las consecuencias de haber crecido durante esa década, o paliamos la sensación de vulnerabilidad que siempre nos ha acompañado. $Y$ esas conversaciones suelen comenzar con Lara Bonilla, ministro de Justicia (p. 227).

Se puede concluir que en esta novela se representa una propia memoria comunicativa y marcadamente cotidiana, además de que se trata de una memoria subversiva o, al menos, inarticulada a nivel oficial. Esto se hace notar, entre otros indicios, en el detalle de que Antonio, desde que fue lesionado por una bala perdida en el asesinato de Laverde, boicotea los noticieros en la televisión, que representan un discurso memorístico oficial. En cambio, relata la memoria de los individuos ordinarios afectados, a pesar de no estar involucrados en el narcotráfico, que es transmitida de forma oral en sus correspondencias diarias. En este sentido, las conversaciones con Maya revelan lo que los documentos oficiales y testimonios escritos, como medios estables de una memoria más bien oficial, no contienen. En especial, las conversaciones tematizan el miedo, punto de conexión entre los miembros del colectivo mencionado y, según el narrador, "la principal enfermedad de los bogotanos de mi generación” (Vásquez, 2011, p. 58). Para superar este temor y olvidar el pasado, Antonio comienza a escribir para recordar conscientemente el pasado en una "terapia íntima para el miedo" (p. 66).

En relación con la percepción sensorial, existen más medios materiales en los que se apoyan los recuerdos íntimos de los personajes y que pueden ser considerados como figuras de memoria para el colectivo en cuestión. Uno de los elementos más centrales es el sonido, estimulante principal de los recuerdos en la novela. En este sentido, un casete representa una de las figuras de memoria simbólicas más importantes, pues condensa los recuerdos de los ruidos, junto a la metafórica caída de la sociedad, que están inscritos en él. Contiene la grabación de la caja negra del Vuelo 965 de American Airlines, accidentado en diciembre de 1995, en el cual murió Elaine Fritts, 
esposa de Ricardo Laverde y madre de Maya. El casete aparece por primera vez en la narración cuando Antonio lleva a Laverde a la Casa de Poesía Silva para poder escucharlo, justo antes de ser asesinado en la calle. Dos años más tarde, Antonio recupera esta figura de memoria en la narración de la casera de Laverde, cuya centralidad se evidencia cuando el narrador la escucha también, ya que en esta ocasión el título de la novela es mencionado por única vez en el relato. Antonio describe este ruido, sonido simbólico para su trauma personal y la memoria colectiva de la sociedad colombiana, como uno "interrumpido y por lo mismo eterno, un ruido que no termina nunca, que sigue sonando en mi cabeza desde esa tarde" (p. 83). La declaración de que el ruido es eterno alude a que la memoria misma sufre una fuerte fragmentación y, debido a ello, el trauma de Antonio no puede ser superado.

Otro estimulador de los recuerdos, vinculado a la percepción sensorial, es el olor. Ejemplo de ello es el recuerdo exacto que tiene Antonio de su penúltimo encuentro con Ricardo Laverde, el cual evoca basado en el olor de los excrementos de un asno: "Recuerdo el olor a mierda del animal aunque no recuerdo que cagara en ese preciso momento" (p. 32).

La literatura de Héctor Abad Faciolince también conecta frecuentemente los recuerdos con la percepción de olores, por lo que Díaz Ruiz (2019, p. 86) habla de una narrativa olfativa de la memoria y proporciona múltiples ejemplos para sostener esta idea. En ambos casos, se evidencia la inspiración en la obra de Marcel Proust, escritor que ha ejercido una notable influencia en los dos autores tratados aquí y cuya magdalena ha desatado toda una serie de estudios sobre el rol clave del olfato como estimulante de los recuerdos. Los siete tomos de $\grave{A}$ la recherche du temps perdu fueron leídos por Abad Faciolince (2006) en México durante tres meses intensos de 1978, gracias al permiso de su padre "de no hacer nada, bastaba que leyera y conociera una gran metrópoli", como lo invoca en El olvido que seremos, "con una pasión y una concentración que nunca he vuelto a sentir en ninguna lectura” (p. 193). Por su parte, Vásquez reflexiona sobre las más de mil páginas en el ensayo "Algunas lecciones de Proust”. La novela proustiana, modelo para el discurso del recuerdo, puede ser considerada como uno de los hipotextos omnipresentes para las novelas de ambos autores. De nuevo, la lectura de los mismos textos crea una base para una identidad compartida y, en cierto modo, una memoria en común. 


\section{Los intertextos como figuras de memoria en la narrativa de los dos autores}

En El ruido de las cosas al caer, la posibilidad de expresar la memoria cultural a través de figuras de memoria intertextuales se realiza especialmente a través de los recuerdos del narrador de ciertos textos literarios, como acertadamente observa Aristizábal (2019): "La voz de Antonio en las memorias está repleta de referencias literarias" (p. 43). El epígrafe de este artículo, una cita del libro refiriéndose a la puesta en escena de viva voz de los escritos de Borges, García Márquez y León de Greiff, manifiesta la relevancia de las incorporaciones de estos autores legendarios en esta novela. Además de las referencias a las literaturas internacionales y europeas, es la tradición propiamente colombiana la que juega un rol central en esta novela. De todas formas, una explícita mención de la famosa obra de García Márquez en El ruido de las cosas al caer, debido a la ironía implícita, provoca una insinuación evaluativa sumamente difícil de clasificar. En el relato, se articula una inclemente crítica por la estadounidense Elaine Fritts, en ese momento joven voluntaria en Colombia y futura esposa de Laverde. Julio Laverde, el padre del piloto, le regala a la joven el libro colombiano más conocido, advirtiéndole que "el tipo era un guache pero el libro, por lo que decían, no estaba mal” (Vásquez, 2011, p. 161). A la figura de Elaine, sin embargo, "todo le pareció absurdo y gratuito, y el título, Cien años de soledad, exagerado y melodramático”, opinión que fortalece en una carta a sus abuelos:

Mándenme lectura, por favor, que por las noches me aburro. Lo único que tengo aquí es un libro que me regaló mi señor, y he tratado de leerlo, juro que he tratado, pero el español es muy difícil y todo el mundo se llama igual. Es lo más tedioso que he leído en mucho tiempo [...]. Cuando pienso que ustedes estarán leyendo el último de Graham Greene. Es que no hay derecho (Vásquez, 20II, p. I6I).

Bogoya (2012) opina que la lectura sin complacencias se debe a "la ingenuidad de la tradición" (p. 44) de la lectora extranjera, y reflexiona sobre la complejidad del diálogo intertextual de Vásquez con el autor del boom. Por un lado, hay que tener en cuenta que, en el momento narrado, en 1969, Cien años de soledad todavía no se ha traducido al inglés y, al menos fuera del área hispanohablante, no gozaba de la importancia cultural que ha conseguido desde la traducción por Gregory Rabassa. Por otro lado, resulta necesario considerar la conciencia de Vásquez sobre los paralelismos estilísticos y temáticos — del campo de la memoria colectiva colombiana con el carácter comprometido de la escritura - entre ambos escritores para que 
sea más comprensible este acercamiento provocador y soslayar las evidencias de la influencia: "Entre el elogio y la ironía, desde el ensayo y la ficción el escritor contemporáneo ronda a sus fantasmas no para matarlos ni para sustituirlos, sino para distorsionar su sombra” (Bogoya, 2012, p. 44). Así, para no caer en el error de clasificar esta alusión precipitadamente como mero rechazo de la escritura de García Márquez, resulta pertinente consultar la opinión de Vásquez, expresada en su obra ensayística. En vez de un elogio simplificado del nobel y la reducción al realismo mágico, Vásquez (2009) intenta aclarar ciertos "Malentendidos alrededor de García Márquez", en un ensayo con este título. En esta línea, en "El arte de la distorsión”, propone malinterpretar a propósito a Cien años de Soledad, leyéndola como novela histórica (p. 36). A pesar de no evidenciar demasiado la relación, Vásquez no niega la posición preeminente de la obra anterior y sigue el legado literario, en cierta manera heredado, con respetuosa atención: "no hay otras páginas de la ficción colombiana que haya leído más veces” (p. 39). En El ruido de las cosas al caer incluso se hacen notar paralelismos textuales entre el inicio de Cien años de Soledad y la descripción de la tragedia aérea de Santa Ana en 1938, ocurrida en el acto conmemorativo del cuadrigentésimo aniversario de la fundación de Bogotá, evocando ciertos recuerdos de la novela clásica: "Muchos años después, recordando ese día aciago, Julio Laverde [...] [r]ecordaría a su padre llevándolo a pie desde la casa de la familia hasta el Campo de Marte” (Vásquez, 2011, p. 112), donde los aviones le parecían "grandes peces prehistóricos" (p. 118). Por un lado, el hipotexto Cien años de Soledad se puede clasificar como una novela escrita en el modo monumental, ya que la voz auctorial y cuasi-celeste del narrador, la ausencia de fechas exactas y la consiguiente universalidad del relato sobre el origen fundacional de Macondo contribuyen a que se lea según este registro literario, asociado con lo épico-mítico de una cultura (Homann, 2020, p. 330). Por otro lado, el episodio mencionado sobre un acontecimiento decisivo en la vida del bisabuelo de Maya Fritts, en un origen fundador y remoto de la memoria familiar de la hija del piloto, constituye una excepción en cuanto al registro literario mayoritariamente aplicado por Vásquez en su novela. En esta ocasión, sale del horizonte social cercano para entrar en un horizonte cultural lejano, con un modo narrativo marcadamente monumental y épico. Para este propósito de ubicar el relato en la dimensión cultural de la memoria, las evocaciones de la obra clásica de García Márquez resultan más que apropiadas. 
También la poesía lírica y las referencias a poetas renombrados tienen un papel central en la narrativa de Juan Gabriel Vásquez. En la novela de 2011, en la que "el discurso literario es siempre protagonista y juega un papel importante en esa necesidad de entender" (Aristizábal, 2019, p. 42) el pasado, este discurso literario es caracterizado por una llamativa estética musical y sonora. En este contexto, resulta fructífero que De Maeseneer y Vervaeke (2020) se acerquen a la novela a través de una aplicación de los Sound Studies: "Las referencias auditivas permiten abordar el pasado de forma distinta y complementaria a las visuales", ya que "aportan un alto nivel de sonoridad a la novela como manera de bregar con el pasado lastimoso" (p. 421). Los dos autores relacionan los sonidos incorporados en la novela con las resonancias intertextuales y con la participación activa de los lectores (p. 421).

Con respecto al género en cuestión, resulta significativo que el término de la lírica procede etimológicamente del instrumento lira y, por ende, del ámbito musical. De la relación estrecha con la oralidad y la música puede deducirse que la poesía vive, al menos en parte, en dependencia de su puesta en escena de viva voz. Héctor Abad Faciolince (2011) opina que la voz del narrador en la novela de Vásquez es "íntima y extraña al mismo tiempo, una voz afinadísima, musical, una voz compleja y serena a pesar de lo atormentada, una voz tan humana que uno dice: a este tipo yo le creo todo lo que me cuente, así sea mentira" (párr. 3). En cuanto a la intimidad y musicalidad de la voz, es revelador que Vásquez se considere a sí mismo, como escritor, un obsesionado de la poesía lírica. En esta línea, incluye poemas y elementos líricos en su narrativa para mejorar el sonido, lo que explica en la entrevista ya citada con De Maeseneer y Vervaeke (2013): “Tengo una concepción poética de la escritura de novelas. Para mí el valor supremo en un párrafo es cómo suene. Cómo suena la prosa, es lo que me dicta lo que pasa en la novela" (p. 211). En cuanto a la conseguida musicalidad de su literatura, menciona: "Las lenguas tienen ritmos que le son naturales, y su poesía clásica generalmente está escrita en estos ritmos” (p. 212). Con esto se refiere al octosílabo y al endecasílabo como versos naturales para confirmar: "Si a uno le preocupa la escritura de ficción con los criterios de un poeta, inevitablemente acaba entrando en estas obsesiones" (p. 212). De ahí que el título El ruido de las cosas al caer sea un endecasílabo.

En cuanto a poner en escena a la palabra poética, en esta novela sobresale el rol central de un poema recitado en voz alta. En la escena ya mencionada en la que 
Laverde escucha el casete de la grabación de la caja negra del avión accidentado, Antonio goza en el museo de poesía de la lectura del "Nocturno III" de José Asunción Silva y de su ritmo particular en una grabación con la música de un piano en el fondo. En esta escena, "la poesía es, por una parte, el elemento estable al que se aferra el narrador ante la irrupción de la violencia en su vida personal, y, por otra, desconcertante en su capacidad de darle formas anticipadas a la realidad y prever futuras violencias"(Aristizábal, 2019,p. 42). Aquí se nota en qué extraordinaria medida la lírica, manifestada por un yo nostálgico, sirve para expresar los recuerdos íntimos, a través de los cuales el narrador trata a la vez la memoria colectiva de la sociedad en la que vive. El hecho de disfrutar de la lectura del poema modernista de una manera ensimismada corresponde con que el discurso memorístico en este relato es también relativamente personal e individual, a pesar de que se pueda extender a una memoria social. Ello corrobora que en la novela podemos detectar con facilidad este juego entre memoria individual y colectiva a través de la escucha muy íntima de un poema, que es soporte de la identidad colectiva, gracias a que forma parte de la tradición cultural colombiana. En 1996, cuando se conmemoraba el centenario del suicidio del poeta, Antonio comenta que "Silva y su obra estaban en boca de todos" (Vásquez, 2011, p. 45). De tal manera, la poesía ayuda al narrador a articularse a través versos conocidos que funcionan como referencias culturales, pues "todo colombiano ha dicho en voz alta alguna vez... 'Una noche toda llena de perfumes / De murmullos y de música de alas”'(p. 46). Así, Vásquez recurre a la memoria cultural de su país para evocar recuerdos colectivos a la hora de describir las experiencias netamente personales de su narrador. Además de esta referencia a Silva, se encuentran alusiones intertextuales a los poetas León de Greiff y Aurelio Arturo con una considerable relevancia para la trama (González, 2016, pp. 484-487), que tienen la misma función de basarse en referentes importantes de la memoria cultural colombiana para expresar recuerdos a la vez individuales y colectivos. Al final del relato, la incorporación del poema "Ciudad de sueño" de Arturo establece el vínculo entre la caída de las cosas y la metafórica de su propia ciudad, la cual se extiende, a un nivel más amplio, a la sociedad colombiana.

Con respecto a Héctor Abad Faciolince, se puede confirmar que la presencia de García Márquez también es palpable en la mayoría de sus obras. A pesar de que en El olvido que seremos solo se encuentra una mención explícita acerca del interés del escritor en conocer al nobel, las referencias y los paralelismos resultan evidentes 
en La Oculta: de manera semejante a la novela clásica del realismo mágico, una casa refleja la vida de una familia — los Buendía y los Ángel—y esta, a su vez, la evolución de toda una sociedad, por lo que representa una memoria social de un colectivo.

Resulta llamativa la cantidad de poemas a los que recurre el autor antioqueño para expresarse en sus textos narrativos, pese a que la poesía es "el género para el que yo creía estar mejor dotado, [...] y siempre que me ha salido un endecasílabo o un alejandrino, he preferido siempre, en vez de publicarlo, disimularlo dentro de un párrafo de prosaica prosa" (Abad Faciolince, 2006, p. 196). Abad Faciolince aprovecha pues los mismos mecanismos que usa Vásquez para escribir una prosa narrativa notablemente sonora y musical, influida en alta medida por la poesía. Este recurso de apoyarse en las capacidades expresivas del género lírico le permite articular de manera adecuada los recuerdos y sentimientos íntimos del yo, puestos en escena en la ficción. Ante todo, son los sonetos que juegan un rol clave, ofreciéndose por su forma clásica de versos endecasílabos, uno de los ritmos preferidos por ambos autores. Por ejemplo, en La Oculta, el padre fictivo Cobo escribe un soneto a la finca de la familia para manifestar la identificación extraordinaria con la casa, leitmotiv de la novela. En general, muchos sonetos tratan temáticamente, además del aspecto amoroso, el carácter transitorio de la vida. Abad Faciolince tematiza este aspecto en El olvido que seremos de manera específica en vinculación con el carácter efímero de los recuerdos, constituyendo el olvido - el título del último capítulo del libro - como la principal preocupación del autor con respecto a la relación triangular entre memoria, vida y muerte. De este modo, incrusta en dicho capítulo la tercera estrofa, o sea, el primer terceto del soneto “AAh de la vida!" de Francisco de Quevedo, para entablar las reflexiones finales de su novela (Abad Faciolince, 2006, p. 274). Anteriormente, y parar aludir a la fugacidad de la vida humana, se transcribe de forma completa la elegía famosa del siglo xv "Recuerde el alma dormida", poniendo en escena los conceptos claves de tempus fugit y memento mori. Abad Faciolince explica la omnipresencia de este poema canónico en su vida con el siguiente comentario:

Algunas de las Coplas de don Forge Manrique por la muerte de su padre, las recitó tantas veces de memoria mi papá en nuestras largas caminatas por el campo, que acabé por aprendérmelas yo también de memoria, y creo que me acompañarán, como lo acompañaron a él, toda la vida (p. 229).

Resulta obvio en qué medida se ofrece este poema para compartir los recuerdos a su padre asesinado. Todas estas referencias sirven para inscribir su literatura en una 
larga tradición. De todas formas, es precisamente el soneto "Aquí/Hoy", el poema encontrado después del asesinato en 1987, el que cobra gran protagonismo tanto en El olvido que seremos como en el relato "Un poema en el bolsillo" de Traiciones de la memoria. El texto ensayístico publicado en 2010 trata sobre la investigación que ha realizado Abad Faciolince sobre el origen y la autoría del texto, cuyo primer verso constituye el título de la novela de 2006; la consulta de veinte fuentes primarias y cientos de documentos le lleva a la convicción de que Borges era realmente el creador del texto original. El escritor medita sobre las relaciones entre la autoría literaria y el fenómeno complejo de la intertextualidad, argumentando que resultaba necesario recurrir a este poema y darle una nueva función en su novela para que no caigan en el olvido ni los logros y la vida del médico Héctor Abad Gómez ni el hipotexto poético. Así concluye su reflexión sobre la importante función de los juegos intertextuales en todos los actos de rememoración: "gracias a que he tratado de no olvidar a esta sombra, mi padre [...], unas letras manchadas por los últimos hilos de su vida [han] rescatado, sin pretenderlo, para el mundo, un olvidado soneto de Borges sobre el olvido" (Abad Faciolince, 2010, p. 180). De tal manera, este poema se convierte en una figura de memoria, lo que subraya la universalidad funcional del hipotexto borgesiano, con los incontables significados que pueden tener los poemas líricos para los lectores.

En conclusión, se destacan llamativos paralelismos entre la narrativa de los dos escritores. En los textos estudiados se ha puesto de manifiesto que se escenifica una memoria comunicativa, que se representa en un modo narrativo asociado a la experiencia, y se narra sobre el pasado reciente y experimentable para los protagonistas y lectores. A pesar de que sigue detectable una influencia de la tradición colombiana, la de García Márquez en concreto, las nuevas propuestas narrativas que tratan la memoria de su área cultural se alejan de los modos épicos y universales para desviar el enfoque hacia las experiencias inmediatas de los protagonistas, con frecuencia personajes de llamativo carácter autoficcional, en un horizonte social cercano. Esto queda también reflejado en las instancias narrativas, con la aplicación habitual de un relato desde un yo, a su vez llamativamente emblemático para un colectivo más amplio. No obstante, esta identificación entre individuo y colectivo cultural es posible gracias a la recurrencia a determinadas figuras de memoria, cuya representación en los textos literarios tiene múltiples significados y funciones para la narración. Una función primordial de las referencias a la tradición literaria es la de ofrecer puntos de apoyo para la memoria, ya 
que ciertos recuerdos colectivos están condensados en los textos literarios y estos se activan a través del uso dado por el narrador, ese yo a la vez personal y representativo para una comunidad. Los mismos hipotextos literarios, referenciados como manifestaciones artísticas y monumentales en los textos nuevos, pueden convertirse así en tales figuras de memoria y generar la sensación de recordar un pasado compartido, representado en la literatura. En este sentido, además de constituir un aspecto fundamental para el análisis de textos narrativos, las inserciones de textos clásicos contribuyen en gran medida a la transmisión de ciertos recuerdos identificadores del colectivo. El que ambos autores recurran con frecuencia a otros géneros y textos anteriores con este propósito demuestra la pertinencia de apropiarse en cierta manera de la palabra literaria o artística ajena. Además de las referencias a García Márquez, la memoria cultural se apoya en las puestas en escena de las creaciones de determinados poetas, colombianos y argentinos —en todo caso, latinoamericanos-, lo que propicia el tratamiento de una temática social y colombiana desde una perspectiva no oficial. De esta manera, Héctor Abad Faciolince y Juan Gabriel Vásquez hacen suyas las voces de la tradición.

\section{Referencias bibliográficas}

Abad Faciolince, H. (2006). El olvido que seremos. Bogotá: Planeta.

Abad Faciolince, H. (2010). Traiciones de la memoria. Madrid: Alfaguara.

Abad Faciolince, H. (2011). La música del ruido. El Espectador (5 de junio). Recuperado de https:// www.elespectador.com/opinion/la-musica-del-ruido-columna-275098/ [05.03.2021].

Aristizábal, J. (2019). Mausoleos y formas sin nombre: Escritura y violencia en Tomás González y Juan Gabriel Vásquez. Revista de Estudios Hispánicos 53 (1), pp. 37-58. DOI: https://doi.org/10.1353/ rvs.2019.0001

Assmann, J. (2011). Historia y mito en el mundo antiguo: los orígenes culturales de Egipto, Israel y Grecia. Madrid: Gredos.

Bogoya, C. (2012). Posturas e imposturas en la nueva narrativa colombiana: el caso de Juan Gabriel Vásquez o el arte de la traición. Les Ateliers du SAL 0, pp. 38-48.

Camarero, J. (2008). Intertextualidad: redes de textos y literaturas transversales en dinámica intercultural. Barcelona: Anthropos.

Capote, V. (2019). Narrativas del yo, intertextualidades y parodias: Las dinámicas de la edición global. En C. Quesada Gómez y K. Vanden Berghe (Coords.). El libro y la vida: ensayos críticos sobre la obra de Héctor Abad Faciolince (pp. 33-50). Liège, Medellín: Presses universitaires de Liège, Universidad Eafit. 
De Maeseneer, R. \& Vervaeke J. (2013). Un fósforo en la oscuridad: Conversación con Juan Gabriel Vásquez. Confluencia 28 (2), pp. 209-216.

De Maeseneer, R. \& Vervaeke, J. (2020). Sensaciones, sonidos y silencios en El ruido de las cosas al caer de Juan Gabriel Vázquez. Revista Chilena de Literatura 101, pp. 405-425. DOI: 10.2307/26915670

Díaz Ruiz, F. (2019). Memoria, privacidad y epifanía: una narrativa olfativa. En C. Quesada Gómez y K. Vanden Berghe (Coords.). El libro y la vida: ensayos críticos sobre la obra de Héctor Abad Faciolince (pp. 85-100). Liège, Medellín : Presses universitaires de Liège, Universidad Eafit.

Erll, A. (2012). Memoria colectiva y culturas del recuerdo: estudio introductorio. Bogotá: Universidad de los Andes.

González, A. (2016). Entrando en materia: novela, poesía y cultura material en El ruido de las cosas al caer. Cuadernos de literatura 20 (40), pp. 465-477. DOI: https://doi.org/10.11144/Javeriana.cl20-40.emnp

Homann, F. (2020). Autenticidad, mito, los modos de transmitir experiencias y el modo monumental en la narrativa colombiana. Caderno de Letras 37,pp. 319-340. DOI: https://10.15210/cdl.v0i37.18793

Lachmann, R. (2010). Mnemonic and Intertextual Aspects of Literature. En A. Erll et al. (Coords.). A companion to cultural memory studies (pp. 301-310). Berlín, Nueva York: De Gruyter.

Scheiding, O. (2005). Intertextualität. En A. Erll y A. Nünning (Coords.). Gedächtniskonzepte der Literaturwissenschaft (pp. 53-72). Berlín, Nueva York: De Gruyter.

Vásquez, J. G. (2009). El arte de la distorsión. Madrid: Alfaguara.

Vásquez, J. G. (2011). El ruido de las cosas al caer. Madrid: Alfaguara. 